\title{
A Relational Altmetric? Network Centrality on ResearchGate as an Indicator of Scientific Impact
}

\author{
Christian Pieter Hoffmann \\ Institute for Media and Communications Management, University of St. Gallen, Blumenbergplatz 9, 9000 St. \\ Gallen, Switzerland. E-mail: christian.hoffmann@unisg.ch \\ Christoph Lutz \\ Institute for Media and Communications Management, University of St. Gallen, Blumenbergplatz 9, 9000 St. \\ Gallen, Switzerland. E-mail: christoph.lutz@unisg.ch \\ Miriam Meckel \\ Institute for Media and Communications Management, University of St. Gallen, Blumenbergplatz 9, 9000 St. \\ Gallen, Switzerland. E-mail: miriam.meckel@unisg.ch
}

\begin{abstract}
Social media are becoming increasingly popular in scientific communication. A range of platforms, such as academic social networking sites (SNS), are geared specifically towards the academic community. Proponents of the altmetrics approach have pointed out that new media allow for new avenues of scientific impact assessment. Traditional impact measures based on bibliographic analysis have long been criticized for overlooking the relational dynamics of scientific impact. We therefore propose an application of social network analysis to researchers' interactions on an academic social networking site to generate potential new metrics of scientific impact. Based on a case study conducted among a sample of Swiss management scholars, we analyze how centrality measures derived from the participants' interactions on the academic SNS ResearchGate relate to traditional, offline impact indicators. We find that platform engagement, seniority, and publication impact contribute to members' indegree and eigenvector centrality on the platform, but less so to closeness or betweenness centrality. We conclude that a relational approach based on social network analyses of academic SNS, while subject to platform-specific dynamics, may add richness and differentiation to scientific impact assessment.
\end{abstract}

\section{Introduction}

Recently, the educational publisher Elsevier took over the online reference management service Mendeley for a sum

Received April 29, 2014; revised July 30, 2014; accepted September 2, 2014.

(C) 2015 ASIS\&T • Published online in Wiley Online Library (wileyonlinelibrary.com). DOI: 10.1002/asi.23423 speculated to be between 69 and 100 million US Dollars. ${ }^{1}$ Only a few weeks later, Bill Gates, along with other investors, invested 35 million US Dollars in ResearchGate, a leading social networking site (SNS) for academics. ${ }^{2}$ These developments document a significant interest in social media tools in the field of scientific communication. A number of social media platforms have found avid use within the scientific community: Prominent researchers, such as Fields Medalwinning mathematician Terence $\mathrm{Tao}^{3}$ and media scientist danah boyd, ${ }^{4}$ use blogs to share their thoughts, publish ad-hoc research, or collect feedback from the scientific community. Twitter has become a powerful communication tool for purposes as diverse as networking, information gathering, knowledge dissemination, and conference chatter (Mahrt, Weller, \& Peters, 2013; Nentwich \& König, 2012). Academic social networking sites, like ResearchGate, Mendeley, or Academia.edu, boast up to several million users.

Despite anecdotal evidence on the increasing popularity of social media in scientific communication, little is known about researchers' adoption of these media: Do scientists use social media to promote their output and enhance their standing within the community (i.e., to generate impact)? Is the number of online contacts or followers related to a scholars' standing within the community? How do offline measures of scientific impact, such as academic position,

${ }^{1}$ http://techcrunch.com/2013/04/08/confirmed-elsevier-has-boughtmendeley-for-69m-100m-to-expand-open-social-education-data-efforts/

${ }^{2}$ http://www.ft.com/cms/s/0/6379b274-cd09-11e2-90e800144feab7de.html\#axzz2Vus8QldZ

${ }^{3}$ http://terrytao.wordpress.com

${ }^{4}$ http://www.zephoria.org/thoughts 
seniority, or number of citations, relate to new online measures of impact?

This paper contributes to the state of knowledge on social media use in academia by focusing on the latter question: We collected use data on the academic networking platform ResearchGate generated by members of the business department of a Swiss university to explore whether scientific impact could be estimated by applying a network analysis approach to social media data. We tested the relationship between relational metrics and various more established measures of impact. Our analysis thereby also contributes to the current debate on impact assessment employing online data ("altmetrics") by adopting a relational, personal networking perspective (Priem \& Hemminger, 2010). To date, network centrality measures derived from social network analysis of academic SNS have not been considered in the context of impact assessment. Our results, while based on a small, exploratory study, suggest that such measures do relate to established impact metrics and therefore might be helpful, at least in complementing existing forms of impact assessment.

\section{Background}

\section{Social Media Use in Academia}

Social media are becoming more and more popular in scientific communication (Bik \& Goldstein, 2013; Priem, 2013). They provide a channel for the speedy dissemination of research results and the interaction with both peers and lay audiences. The open access philosophy further strengthens the appeal of social media as a tool for academic communication (Mounce, 2013; Nielsen, 2012). Increasingly, institutional imperatives, such as pressure by funding agencies and grant committees, drive researchers to display the importance of their work online. ${ }^{5}$

Key terms like open access, open data, science 2.0, cyberscience, or networked science (Nentwich \& König, 2012; Nielsen, 2012) emphasize the contribution of new communication technologies to sharing and collaboration in research - and the connection of diverse cooperation partners and audiences. Today, the coauthorship of scientific papers is easier to organize and more common than 20 years ago due to the affordances of new communication technologies (Glänzel \& Schubert, 2005). Social media are especially effective in establishing and managing personal connections. Blogs, Twitter, and academic social networking sites enable more flexible forms of both cooperation and publication than traditional outlets, such as conferences and journals (Desai et al., 2012; Eysenbach, 2011; Priem \& Costello, 2010; Shema, Bar-Ilan, \& Thelwall, 2012).

Considering the potential impact of social media on scientific communication practices, only limited research has been directed at their adoption and effects in the scientific community. To date, most findings are exploratory and

\footnotetext{
${ }^{5}$ http://www.nsf.gov/social/policies.jsp
}

descriptive in nature: Procter et al. (2010) found that Web 2.0 adoption among scientists is influenced by demographic characteristics, such as age (the younger, the more frequent social media use), gender (males being more frequent users), but also by position and discipline. As for the last factor, "computer scientists and mathematicians" exhibit the highest percentage of frequent use (26\%; Procter et al., 2010, p. 4043). The authors also showed that collaboration practices, support, skills, and attitudes play an important part in shaping scholars' adoption of Web 2.0 applications.

More recently, Gruzd and Goertzen (2013) conducted an online survey among the members of three professional social science organizations. Based on uses and gratifications theory, they identified key motives for social media use among academics, such as "keeping up to date with topics," "following other researchers' work," and "discovering new ideas or publications" (Gruzd \& Goertzen, 2013, p. 3337). Overall, information uses are more prevalent than communication and networking uses. The survey also revealed that, currently, nonacademic SNS and blogs are the most popular applications for frequent use, followed by online document management services. When it comes to future use intentions, though, academics are most likely to adopt presentation sharing sites, bibliographic management sites (e.g., Mendeley), and academic social networking sites (e.g., Academia.edu or ResearchGate).

Given their comparatively recent establishment, it is not surprising that little research has investigated academic SNS, their structure, mechanisms, and use. Social networking sites have been defined as: "web-based services that allow individuals to (a) construct a public or semi-public profile within a bounded system, (b) articulate a list of other users with whom they share a connection, and (c) view and traverse their list of connections and those made by others within the system" (boyd \& Ellison, 2007, p. 211). Academic social networking sites, like Academia.edu and ResearchGate, fulfill all of these criteria. They are geared towards an academic audience, however, and include additional functions, such as uploading and sharing articles, endorsing colleagues, or finding literature (Jeng, He, \& Jiang, 2014; Thelwall \& Kousha, 2014a, 2014b).

Our study focuses on the academic SNS ResearchGate. According to its own reports, ResearchGate has 4 million members as of July 2014. A large part of the membership base stems from medicine and biology. In general, natural sciences figure more prominently on the platform than social sciences and humanities. On ResearchGate, users can establish a personal profile with academic information, share publications and data sets, engage in discussions, up/downvote publications and discussion topics, write messages, search for and monitor peers as well as their own impact via the ResearchGate score (Giglia, 2011). The platform shares many functions with user-centric services such as Facebook and LinkedIn, but is expressly geared towards a scientific audience. In a recent study, Thelwall and Kousha (2014a) found that ResearchGate usage data may indicate esteem or influence within the scientific community. 


\section{Measuring Scientific Impact}

Today, scientific impact is primarily estimated based on bibliographic metrics (see Bollen, Van De Sompel, Hagberg, \& Chute, 2009, for an overview). Citations and publications in peer-reviewed journals are the key indicators of academic merit. While on the journal level the most prominent measure is the impact factor (Garfield, 2003), the h-index has emerged as a popular metric focusing on the individual researcher (Hirsch, 2005). Both measures have been criticized on various grounds:

While bibliographic metrics do indicate a degree of peer attention, journal publications are not the only source of scientific impact (Public Library of Science [PLoS] Medicine Editors, 2006). Impact, understood as a researcher's esteem and influence within the scientific community, relates to the dynamics of scientific communication. As the tools of scientific communication evolve, new opportunities to assess impact arise-and traditional tools, such as journal-based bibliometrics, become more contested (Priem, 2013).

Critics point out that impact measures based on journal publications and corresponding databases make disciplines where other forms of publication are common difficult to evaluate. "Alternative" forms of publication that all too often fly under the radar of common metrics include books (liberal arts, linguistics, social sciences), reports, presentations, or conference proceedings (computer science). New possibilities of sharing output, such as data sets or code, are not reflected in traditional measures either (Seglen, 1997). The context of citations (i.e., why and how certain articles were cited) is also neglected in traditional metrics (PLoS Medicine Editors, 2006).

We identify two theoretical angles from which traditional bibliographic impact measures have been scrutinized. First, they are criticized for undervaluing informal aspects of academic influence, such as commitment to the community, embeddedness in research groups, or outreach beyond the scientific community (PLoS Medicine Editors, 2006). In other words, the role of social networks has been underestimated in traditional impact evaluation. The concept of invisible colleges captures important aspects of scientific communities in terms of networking and social relations (Crane, 1972):

"Members (of invisible colleges) convene meetings; talk to and write other members; battle over claims and theories; exchange drafts, preprints, and reprints of their articles for critical scrutiny; and routinely enter into various forms of collaboration, including co-authorships" (White, 2011, p. 275). Within invisible colleges, core members-or influentials - can be detected with social network analysis (SNA), using centrality measures. Therefore, applying a relational perspective to scientific impact assessment may provide a promising avenue of evaluation (Dimitrova et al., 2013; Koku, Nazer, \& Wellman, 2000; White, Wellman, \& Nazer, 2004).

In fact, studies employing a relational perspective and relying on SNA are well established in the social sciences
(Freeman, 2004). They analyze forms of relationships between individuals, in some cases focusing on the academic community (White, 2011). Here, possible forms of relations range from acquaintances and comemberships in professional organizations, to virtual communication exchange via e-mail or social media, to coauthorship, and author-intercitation (Moody, 2004; Yan \& Ding, 2009, 2012). Webometric network analyses have also been applied to scientific communication to identify cooperation structures and explore the prominence of specific actors (institutions as well as individuals) (Thelwall \& Harries, 2004; Thelwall, Sud, \& Wilkinson, 2012).

A second theoretical criticism of bibliographic measures is based on capital theories. Bourdieu famously discussed traditional criteria of academic influence and power (Bourdieu, 1990). In his categorization of capital forms in academia, Bourdieu distinguished more external and economic forms from more internal ones: He described institutional power at the university level (e.g., being a dean) as an indicator of external capital, and peer reputation (managing a research team, being on an editorial board, etc.) as an indicator of internal capital.

While traditional bibliographic measures of impact do include a seniority component, as they need time to accumulate, they are slow to adapt to changes in social status or relational capital (Bornmann, 2013; Bornmann \& Daniel, 2008; Eysenbach, 2011). Again, observing the social relations between researchers may provide a promising approach to the consideration of academic capital in impact assessment, as personal associations mirror both the influence of individual actors and the mutual esteem between network participants (see Thelwall \& Kousha, 2014a). Bourdieu reminds us that the realm of statements (i.e., scientific publications) is a mere expression of the actual social space (Bourdieu, 1984, 1996). It is the distribution of field-specific capital that determines how and what scholars are able to achieve (Bourdieu, 1990).

\section{New Approaches: Altmetrics}

New opportunities to assess scientific impact emerge as scholarly communication evolves. Currently, alternative metrics of scientific impact based on online media are being developed and tested. Still in its infancy, the altmetrics approach constitutes a promising field of inquiry. This is especially true because social media provide a wealth of data, and thereby increase the transparency of scientific communities (Priem, 2013; Priem \& Hemminger, 2010). By making connections visible and by analyzing social media data, social scientists gain new insights into the structure and dynamics of academic work.

The Altmetrics Manifesto compiles a compact summary of the goals and scope of the altmetrics approach (Priem, Taraborelli, Groth, \& Neylon, 2010). Impact metrics are described as multifaceted constructs, comprised of four pillars: usage, peer review, citations, altmetrics. Commonly, altmetrics are not held to replace traditional, bibliometric 
measures of academic influence. They are suggested to complement and question them: The altmetrics service ImpactStory, for example, collects data from social media outlets, ranging from general purpose applications, like Twitter, Wikipedia, and Facebook, to specific academic solutions, such as Mendeley and PLoS. It then creates a report including statistics from all the platforms considered (likes, retweets, downloads, citations). The service demonstrates the multifaceted nature of scientific communication, collaboration, and outreach.

Webometrics and altmetrics can be applied at the level of a journal (Thelwall, 2012; Vaughan \& Hysen, 2002), a single article (Kousha, Thelwall, \& Rezaie, 2010; Vaughan \& Shaw, 2003), or an individual researcher (Aguinis, Suárez-González, Lannelongue, \& Joo, 2012). In their roadmap, the authors of the Altmetrics Manifesto call for research that compares altmetrics with other measures of academic influence: "Researchers must ask if altmetrics really reflect impact, or just empty buzz. Work should correlate between altmetrics and existing measures, predict citations from altmetrics, and compare altmetrics with expert evaluation" (Priem et al., 2010).

Some social media services have reacted to the emergence of altmetrics by providing their own online metrics of impact. ResearchGate, for example, calculates a "ResearchGate Score" for each of its members. The score is comprised of four indicators: number of publications, questions asked in the community, answers given in the community, and number of followers. To date, the company has not released the exact formula underlying its impact score. Given its composition, it is geared to encourage platform engagement among users.

\section{Research Framework}

Altmetrics provide a promising approach to complementing scientific impact assessment. Yet even these new metrics do not sufficiently address the criticism just outlined: a lack of regard for the social embeddedness of research and scientific communication and the importance of academic capital for the development of scientific impact. At the same time, we have seen that social network analysis has been applied to impact assessment, primarily in the analysis of web links and coauthorship networks (Yan \& Ding, 2009). We hypothesize that academic SNS may allow for new metrics of scientific impact, focusing on the relational dimension of communication and influence because these SNS allow users to articulate and manage their personal networks (boyd \& Ellison, 2007). Network analysis, in turn, reveals a member's centrality within a network, which can be (and commonly is) interpreted as a measure of prominence and influence (Wasserman \& Faust, 1994). Previous studies have shown that members use academic SNS to keep up-to-date on colleagues' research. Structural analyses of follower and followee relationships within these SNS networks could therefore contribute to an understanding of individual members' esteem within the community.
Also, platform members reportedly employ these tools to build up personal networks as they establish and develop their position within the scientific community (Jeng et al., 2014). A structural analysis might therefore indicate the distribution and accumulation of academic capital. Thelwall and Kousha (2014a) conducted an analysis of the academic SNS ResearchGate in order to analyze the relationship between platform use data and the esteem or ranking of academic institutions. Similarly, we propose that a researcher's position within an academic SNS may provide insight into his esteem within the scientific community, and thereby serve as a measure of her scientific impact:

Research Proposition 1: A researcher's network centrality on an academic SNS (in terms of indegree, closeness, betweenness, and eigenvector) is an indicator of his prominence within the scientific community.

A number of factors can be expected to affect a researcher's centrality within an academic SNS. Among these factors are the researcher's activity on the online platform (i.e., her platform engagement), the researcher's seniority, and the impact of his publications:

1. Platform engagement: A key foundation of the altmetrics approach, researchers' activity on social media platforms may indicate their involvement and participation in the scientific community. High levels of activity may contribute to the attention attracted within an online community (see Thelwall \& Kousha, 2014b).

2. Seniority: As described by Bourdieu (1990), academia tends to institutionalize reputation and influence in the form of prizes and awards, formal positions, rankings, or membership in editorial boards. In a study of academic SNS Academia.edu, Thelwall and Kousha (2014b) showed that academics' seniority contributes to the attention attracted on the platform.

3. Publication impact: This traditional, bibliometric measure focuses on a researcher's output as a result of her cooperation and connections within the scientific community. Traditional metrics include journal impact factors or the h-index. Increasingly, the impact of publications can also be gauged online (e.g., in the form of likes, downloads, or shares). The publication record is not only a measure, but also a driver of prestige and reputation within the scientific community-and in online networks (Thelwall \& Kousha, 2014b; Thelwall et al., 2012).

Research Proposition 2: A researcher's prominence in terms of his network centrality on an academic SNS is predicted by her (a) platform engagement, (b) seniority, and (c) publication impact.

\section{Methods}

\section{Data and Methods}

ResearchGate only allows access to the required relational data if a written consent by the respective platform members could be produced. Therefore, we conducted a small-scale, explorative study: 55 faculty members of a 
Swiss public university's school of management agreed to participate in the study. By signing a declaration of consent, they granted access to their interaction data generated on the academic SNS ResearchGate over the course of half a year, from September 2012 until February 2013. The data include information such as follower relationships, likes, shares, or comments. We received the data set from ResearchGate by mid-February 2013, and subsequently analyzed the participants' network structure using SNA (Borgatti, Mehra, Brass, \& Labianca, 2009; Emirbayer, 1997; Scott \& Carrington, 2011; Wasserman \& Faust, 1994).

Study participants cover a wide range of academic positions as well as 12 different, independent organizations (institutes) within the school. The institutes cover various fields of research, such as media and communications, technology management, pedagogy, information science (IS), or marketing. They operate as independent profit centers. Fifty percent of participants are doctoral students/research associates, $30 \%$ are post-docs and junior/assistant professors, and 20\% are full professors. As for gender, 20\% are female and $80 \%$ male (representative of the faculty's gender composition).

We used UCINET/Netdraw (Borgatti, Everett, \& Freeman, 2002) and Gephi (Bastian, Heymann, \& Jacomy, 2009) to analyze and visualize the directed network data. To explain the individuals' network position in terms of centrality we conducted linear regression models in STATA (v. 9, College Station, TX) with robust standard errors (regression diagnostics are available upon request).

\section{Measures}

Platform engagement was measured with a normalized activity index, summing up the following four ResearchGate metrics: number of uploaded full-text publications, number of followings, number of questions, and number of answers given. ${ }^{6}$ These four dimensions largely cover the communication activities facilitated by the platform. We deemed these measures preferable to self-reported data, which may be subject to reply biases (Ellison, Steinfield, \& Lampe, 2007). The use activity in our sample is very unevenly distributed, with 24 out of 55 participants receiving a (prenormalized) index value of 0 , while the maximum value is 76 (see Appendix A1). This uneven distribution is in line with findings on online community engagement in other contexts: Studies have shown that in many online communities, only a small minority contributes the majority of content, while a large majority contributes very little, if anything at all (Ewing, 2008; Nov, Naaman, \& Ye, 2009).

We take the researchers' duration of membership in ResearchGate into consideration as a control variable since it might affect platform engagement: Users more familiar with the platform may be more inclined to engage with

\footnotetext{
${ }^{6}$ Thus, the formula for the activity index $=($ fulltextCount + numFollowings + numQuestions + numAnswers)/max(activity index).
}

colleagues in this environment. We also control for the researchers' publication coverage on ResearchGate by calculating the difference of total publications (according to the university's official publication database) and publications listed on ResearchGate.

We operationalized the Seniority criterion by grouping the sample into five categories according to academic position. We distinguished between undergraduate students (0), doctoral students (1), post-docs and project managers (2), junior/assistant professors (3), and full professors (4).

We used two measures to gauge Publication impact: We employ the term Publication success to denote a traditional "offline" measure of publication impact, the h-index (Hirsch, 2005). The h-index is a widely used measure for publication success and seems to perform relatively well in terms of robustness and prediction power (Hirsch, 2007). Data were collected from Google Scholar, and all listed publications of the sample participants were taken into consideration ("overall h-index"). Where Google Scholar did not provide an overall h-index, the h-index was extracted with Harzing's "Publish or Perish" software (Harzing, 2007). Since the h-index is bounded by the total number of publications, it favors more senior scientists. We therefore take the researchers' total citations and average citations per publication into account as control variables.

In order to reflect the altmetrics approach to impact assessment (Priem et al., 2010), we analyzed a second measure termed Publication resonance. This measure addresses the resonance of publications on ResearchGate and is based on an index comprised of four indicators: publication views, downloads, number of upvoted publications, and number of bookmarked publications. The indicators were weighted according to the level of user engagement they indicate, with upvotes being more heavily weighted than bookmarks and downloads, which in turn are more heavily weighted than views. ${ }^{7}$ We normalized this index so that the maximum value is 1 and the minimum value 0 .

Network centrality was measured with four centrality measures: (in)degree centrality, Freeman's closeness/farness centrality, betweenness centrality, and eigenvector centrality as expressed by Bonacich power (Hanneman \& Riddle, 2011). For indegree centrality we considered both the core network of researchers who signed the consent form $(N=55$; thus the maximum possible value is 54 , and the minimum 0 ) and overall followers (the maximum is the number of ResearchGate users at the time of data collection-1, that is, roughly 3 million, and the minimum again 0 ).

Centrality is an essential concept in SNA and captures a person's prominence within a network. Different centrality have different meanings: indegree, for example, is a person's "visibility" and measures "where the action is"

\footnotetext{
${ }^{7}$ Publication $\quad$ index $=$ publicationViews $+5 *$ publicationDownloads + $10 *$ numUpvotedPublications $+5 *$ numBookmarkedPublications. The weights reflect the fact that downloads and bookmarks indicate a user's intent to read a publication, while an upvote implies that the publication has actually been read.
} 


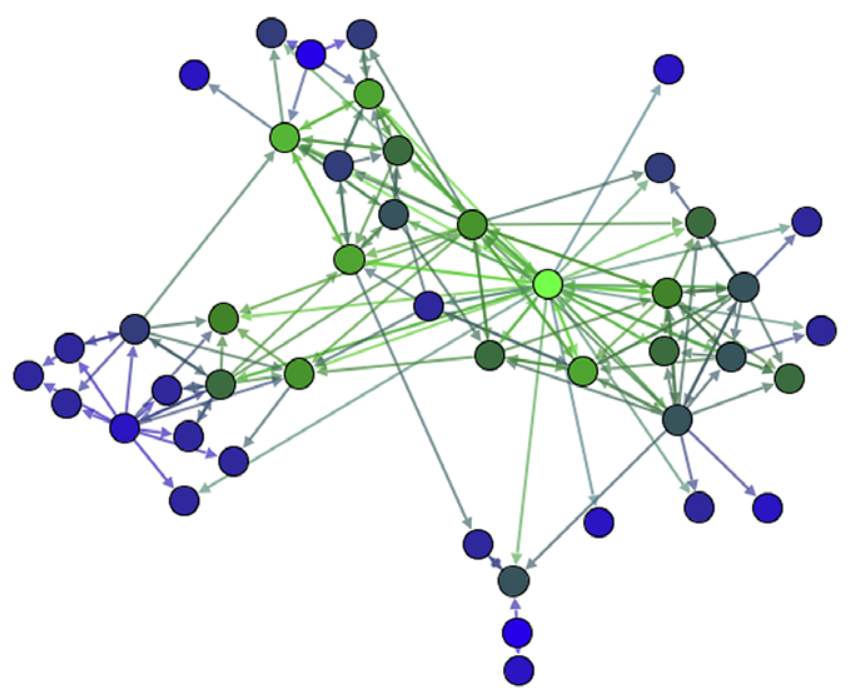

FIG. 1. Network structure of the sample. [Color figure can be viewed in the online issue, which is available at wileyonlinelibrary.com.]

(Wasserman \& Faust, 1994, p. 179), whereas closeness centrality captures how quickly someone in a network reaches others or can be reached (reachability). High indegree centrality on ResearchGate indicates prominence and high visibility of activity or output. By contrast, high scores on closeness centrality indicate that a user can easily connect with other members, for example, through referrals from personal contacts. Similarly, betweenness centrality - which measures bridging, control, or gatekeeping - is an indicator of cluster connection. Hence, high betweenness scores might point to interdisciplinarity and variety in a member's network (see Leydesdorff, 2007). Finally, eigenvector weighs the importance of someone's connections in the network. Being connected to many people who are themselves connected to many others would result in a high eigenvector centrality score. In our case, eigenvector could be interpreted as a measure of resonance or impactful communication.

As mentioned previously, we take the researchers' duration of platform membership into consideration as a control variable. The duration of membership could significantly affect the members' network centrality, since, over time, members have more opportunity to find and connect to colleagues. Also, we control for the researchers' total number of coauthors as listed on ResearchGate, as this variable could also be associated with network centrality. Finally, we also consider the platform's own metric of scientific impact, the so-called ResearchGate Score.

\section{Results}

\section{Descriptive Data Analysis}

Figure 1 shows the structure of the follower network on ResearchGate for our sample $(N=45 ; 10$ isolates not in the graph). Thus, it shows who follows whom within the sample. The coloring indicates the indegree centrality of the
TABLE 1. Basic network metrics of the sample.

\begin{tabular}{lc}
\hline Measure & Value \\
\hline Average Degree Sample & 3.04 \\
Average and Median Indegree Overall & 9.98 / Median: 5 \\
Average and Median Outdegree Overall & 7.74 / Median: 1 \\
Density & 0.06 \\
Clustering Coefficient & 0.48 \\
E-I Index fore Institute Membership & -0.08 (expected: 0.69 ) \\
Average Distance & 2.43 \\
Diameter & 6 \\
Isolates & 10 \\
\hline
\end{tabular}

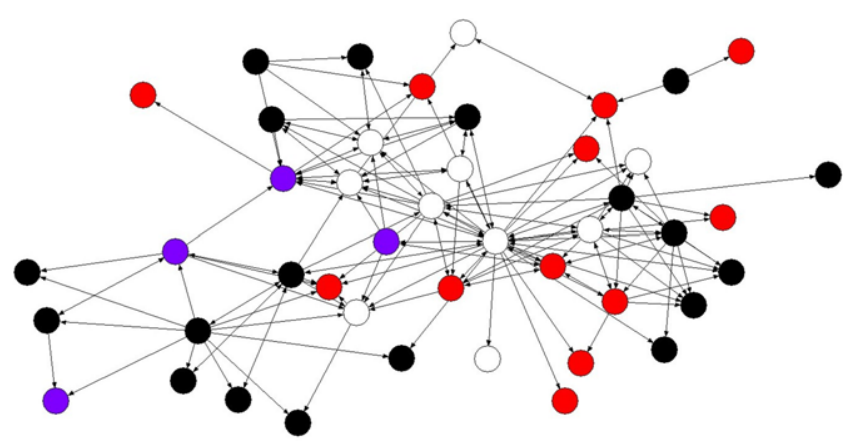

FIG. 2. Network coloring according to academic position. [Color figure can be viewed in the online issue, which is available at wileyonlinelibrary.com.]

nodes with lighter colors indicating higher indegree (dark blue nodes are the least and light green nodes the most central). The graph reveals a connected component, so despite different research foci, most management scholars within the sample are in fact connected on ResearchGate. At the same time, clustering is apparent, which can be explained by institutional homophily. ${ }^{8}$

Table 1 provides basic network statistics of this follower network. With a low average path length and a high clustering coefficient, the network reveals typical attributes of small-world networks (Watts \& Strogatz, 1998). The low value of the E-I Index points to high homophily, which can be expected given that all participants are members of the same faculty. When study participants use ResearchGate for networking, they tend to follow institutional peers they already know rather than establishing new contacts. This fact is compounded by a low density and a relatively high number of isolates.

In our sample, assistant professors occupy the most central positions, not senior faculty (Figure 2; black $=\mathrm{PhD}$; blue $=$ post-doc; red $=$ full professors; white $=$ assistant professors; $N=45 ; 10$ isolates omitted).

\section{Correlation and Regression Analyses}

To gain closer insight into the relationships between the observed variables, we conducted an initial correlation

\footnotetext{
${ }^{8} \mathrm{~A}$ graph with coloring according to institutional association is available upon request.
} 
TABLE 2. Linear regression of network centrality measures on seniority, publication success, publication resonance, engagement, and the ResearchGate score.

\begin{tabular}{|c|c|c|c|c|}
\hline & Indegree & Closeness & Betweenness & Eigenvector \\
\hline Platform Engagement & $\begin{array}{l}0.42 * * * \\
0.52 * * *\end{array}$ & $0.21 * * *$ & n.s. & $0.42 * * *$ \\
\hline \multicolumn{5}{|l|}{$\begin{array}{l}\text { Seniority } \\
\qquad(\text { Master student }=0)\end{array}$} \\
\hline PhD Student (1) & $\begin{array}{l}0.23 * * * \\
\text { n.s. }\end{array}$ & $0.59 * * *$ & n.s. & $0.19 * *$ \\
\hline Post-Doc (2) & $\begin{array}{l}\text { n.s. } \\
\text { n.s. }\end{array}$ & $0.27 *$ & n.s. & n.s. \\
\hline Junior/Assistant Professor (3) & $\begin{array}{l}0.57 * * * \\
0.39 * *\end{array}$ & $0.77 * * *$ & n.s. & $0.61 * * *$ \\
\hline Full Professor (4) & $\begin{array}{l}\text { n.s. } \\
\text { n.s. }\end{array}$ & $0.78 * * *$ & n.s. & n.s. \\
\hline Publication Success (h-index) & $\begin{array}{l}0.48^{* *} \\
0.36^{*}\end{array}$ & n.s. & $0.36^{*}$ & $0.41 *$ \\
\hline Publication Resonance & $\begin{array}{l}0.46 * * * \\
0.38 * *\end{array}$ & $0.39 *$ & n.s. & $0.44 * * *$ \\
\hline RG Score & $\begin{array}{l}-0.70 * * * \\
\text { n.s. }\end{array}$ & $-0.72 * * *$ & n.s. & $-0.76^{* * *} *$ \\
\hline Duration of Membership on RG & $\begin{array}{l}0.19 * * \\
0.16 * *\end{array}$ & $0.30 *$ & n.s. & n.s. \\
\hline Number of Co-Authors & $\begin{array}{l}\text { n.s. } \\
-0.20^{*}\end{array}$ & n.s. & n.s. & n.s. \\
\hline Publication Coverage & $\begin{array}{l}0.26 * * * \\
0.45 * * *\end{array}$ & n.s. & n.s. & $0.20 * *$ \\
\hline $\mathbf{R}^{2}$ & $\begin{array}{l}0.64 \\
0.89\end{array}$ & 0.45 & 0.48 & 0.65 \\
\hline
\end{tabular}

Note. Within Indegree: first row = overall indegree centrality (total number of followers), second row = indegree centrality within the sample (number of followers in the sample). $\mathrm{N}=55$; n.s. = not significant; robust standard errors; standardized regression coefficients. $* p<.1 ; * *<.05 ; * * * p<.01$.

analysis (see Appendix A2). Given our small sample size, the correlation analysis served as a basis for the composition of a parsimonious regression analysis.

We find that platform engagement is strongly correlated with all measures of centrality but not with publication impact or seniority. This implies that network-based measures are related to network-based communication activity, which in turn may be unrelated to traditional measures of impact.

Both publication record measures strongly correlate; they also show a high correlation with seniority, number of coauthors, and the ResearchGate Score. We find that publication resonance on the platform more strongly correlates with the network centrality measures than does publication success. Again, it appears that there are network-specific dynamics that affect the centrality of researchers as well as their publication impact within the online community. Platform engagement does not appear to affect publication resonance.

We find that the h-index measure of publication success correlates so strongly $(>0.9)$ with the total and average number of citations that considering all three variables would engender multicollinearity. We therefore chose only to consider the h-index measure in the regression analysis. Publication record, unsurprisingly, is also closely related to the total number of publications, which in turn highly correlates with seniority.
Seniority is highly correlated with all centrality measures except for betweenness centrality.

In order to address our research propositions, we conducted a linear regression analysis using STATA (see Table 2). We used the option of robust or heteroscedasticityconsistent standard errors to account for possible heteroscedasticity in the data. Given the small sample size and the skewedness of some variables in the data set, relying on normal, nonrobust standard errors could have otherwise resulted in faulty standard errors and inaccurate significance levels.

First, we find that platform engagement is a strong predictor of network centrality in terms of indegree and eigenvector centrality. The more active a user, the better connected in terms of these two criteria. This effect is weaker for closeness centrality and insignificant for betweenness centrality.

Second, seniority is a predictor of network position and influence, yet apparently not in a linear relationship. While $\mathrm{PhD}$ students are more central in terms of indegree, closeness, and eigenvector centrality than master students, junior/ assistant professors are even better connected than $\mathrm{PhD}$ students. Full professors, on the other hand, do not appear more central in the sample and overall network than their more junior colleagues - indicating an inverted $\mathrm{u}$-shape connection between seniority and network centrality. Computing and plotting the average indegree centrality value for 


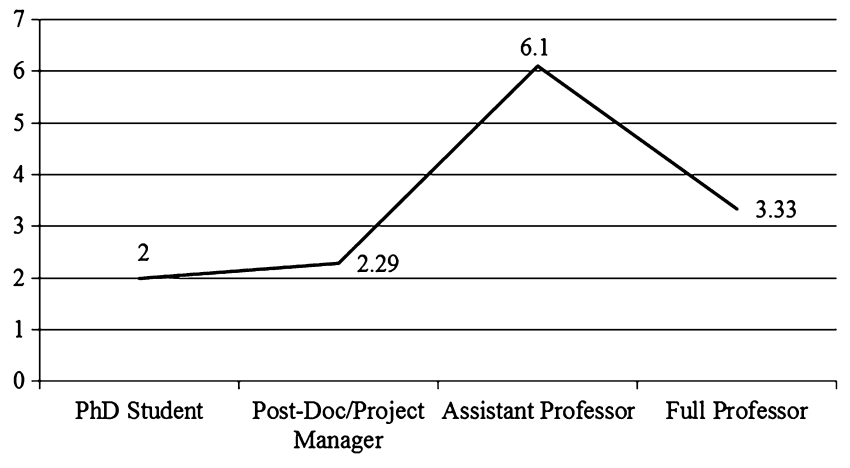

FIG. 3. Average indegree centrality according to academic position.

each seniority category (Figure 3) illustrates an inverted-u shaped rather than a linear relationship (similar patterns emerge for the other centrality measures). We do not find any significant effect of seniority on betweenness centrality.

Third, publication impact affects network centrality, particularly indegree and eigenvector centrality. With respect to these two centrality measures, the publication success variable (h-index) and the publication resonance variable (on ResearchGate) exhibit very similar effects. Publication success also significantly affects betweenness centrality, while publication resonance shows an impact on closeness centrality. Both effects are only significant at the $10 \%$ level, however.

We find that publication coverage positively affects indegree and eigenvector centrality. Researchers with incomplete ResearchGate profiles, accordingly, attract fewer followers. The number of coauthors shows no effect on the researchers' centrality within the overall network, indicating that centrality measures go beyond immediate collaborators. Duration of membership has a significant effect on indegree centrality-the longer researchers are members of the platform, the more chances they have to attract followers. Finally, the platform's own impact metric, the ResearchGate score, has a significant negative effect on the members' centrality. Given that the composition of the score is not disclosed, this rather surprising finding is difficult to interpret. In total, we are able to explain between about $45 \%$ and $89 \%$ of the total variance in the centrality measures.

\section{Discussion and Conclusions}

\section{Summary and Implications}

Institutions are struggling to reliably assess the impact of researchers within the scientific community-among them universities trying to select and incentivize high-impact faculty members. Scientific impact can be understood as a researcher's standing-prominence and influence-within the scientific community. While difficult to conceptualize and measure, this impact is commonly based on successful communication. Since peer-reviewed journals constitute a major outlet of scientific communication, impact assessment has focused on bibliographic metrics estimating the impact of journals or single contributions (Garfield, 2003; Hirsch, 2005). As new tools of scientific communications emerge, new metrics of impact assessment are being proposed (Priem et al., 2010).

Our study addresses criticism aimed at traditional measures of impact assessment, specifically their undervaluing of relational aspects of scientific impact and social capital formation (PLoS Medicine Editors, 2006). While a range of studies indicate that social networks are crucial in driving research disciplines and creating social capital for individual members (Dimitrova et al., 2013; Koku et al., 2000; White et al., 2004), bibliometrics does not sufficiently take account of these dynamics. As SNS facilitate both the management and the analysis of personal networks based on online data, we hypothesize that measures of network centrality derived from academic SNS may provide valuable insights into researchers' prominence within the scientific community, and thereby impact assessment.

Based on a small-scale, explorative study among members of a Swiss university department using academic SNS ResearchGate, we computed centrality measures and analyzed their relationship to traditional measures of impact assessment. We found that the study participants use the academic SNS more as a Facebook-like networking tool than a Twitter-like communication tool (Archambault \& Grudin, 2012; Hughes, Rowe, Batey, \& Lee, 2012; Quan-Haase \& Young, 2010). In general, participants do not follow a large number of their peers. Rather, they primarily interact within their offline community, such as institutional colleagues. The results indicate large institutional homophily. Thereby, the SNS reaffirms rather than extends established communities (Dimitrova et al., 2013).

As to the study's research propositions, the findings indicate that relational measures derived from interactions on an academic SNS are related to more traditional measures of scientific impact. However, they also exhibit some notable platform-specific dynamics: We find that, in our sample, junior faculty are more active within the online community ${ }^{9}$ and hold the most central positions within the network. Platform engagement, in fact, contributes to network centrality (as does - to a lesser degree-duration of membership). This finding could signify that junior faculty members, striving to establish themselves, more actively try to generate social capital through their communication and networking activities - which might translate into impact further down the road (Pénard \& Poussing, 2010; Valenzuela, Park, \& Kee, 2009; Wellman, Quan-Haase, Witte, \& Hampton, 2001). Seniority, instead, clearly does not correspond with higher platform engagement (Jeng et al., 2014; Thelwall \& Kousha, 2014b). Still, senior researchers exhibit significant prominence within the overall network as well as within the sample. Thereby, centrality measures have some correspondence with established indicators of academic capital, but are also subject to platform-specific influences.

\footnotetext{
${ }^{9}$ Assistant professors have an average activity index of 0.27 , while full professors score only 0.11 .
} 
The effect of seniority on network centrality may be mediated through publication impact, as publications have been shown to drive online attention (Thelwall \& Kousha, 2014b). We find that seniority highly correlates with publication impact. Publication impact, in turn, has some effect on network centrality, particularly indegree and eigenvector centrality. Similarly, platform members profit from high publication coverage in the form of increased indegree and eigenvector centrality. Wasserman and Faust (1994) describe indegree centrality as visibility. In our case, those with high indegree-and also eigenvector-scores expose their output to a larger audience. Thus, it does not surprise that they generate more page views and downloads, as captured by publication resonance.

Our analysis finds some support for the altmetrics approach to impact assessment, in that online publication resonance is highly correlated with the traditional offline metric (h-index) and also seniority.

When assessing the contribution of network centrality on an academic SNS to scientific impact assessment, it is worthwhile to differentiate the considered centrality measures: betweenness centrality has been proposed as a measure of academic interdisciplinarity (Leydesdorff, 2007). It is noteworthy that neither platform engagement nor traditional measures of academic capital significantly affect this centrality measure. Therefore, while potentially serving to characterize the work of an academic, it does not seem particularly well suited to inform impact assessment. The reverse holds true for indegree and eigenvector centrality, which have traditionally been interpreted as indicators of visibility, prominence, or "clout," and could similarly be interpreted in impact assessment.

Finally, the relatively low $\mathrm{R}^{2}$ score of closeness centrality indicates that this measure is not strongly associated with a more traditional understanding of scientific impact. At the same time, we find that seniority does affect this measure, as does platform engagement and duration of membership. Closeness centrality has traditionally been interpreted as ease of connecting to other network members. In a longitudinal analysis, it might therefore shed some light on the formation and operation of "invisible colleges" in academia (Crane, 1972).

Of course, as with every metric employed in academic impact assessment, centrality measures derived from a structural analysis of an academic SNS may be subject to biases and prone to "gaming": The size of an academic field or community will influence centrality measures just as it does journal impact factors (Thelwall \& Kousha, 2014a). For disciplines less well represented on academic SNS, such as the humanities, centrality measures will not be very valid measures of scientific impact. The better represented a field, the more valid these measures will become. For our sample of management scholars, we found that a researcher's number of coauthors does not affect network centrality, indicating that the membership base in this field is large enough to drown out such interpersonal effects.

It should also be noted that the relatively strong impact of platform engagement on most centrality measures may devalue their contribution to impact assessment in some eyes. At the same time, these efforts could also denote actual networking activity or community involvement, and thereby inform our understanding of the accumulation of academic capital (Yan \& Ding, 2009). In fact, we find that within the sample, SNS use is not very social at all and barely interactive. More senior academics, in particular, largely limit their engagement to the listing of their publications-yet relationships between platform members may still signify esteem within the community, and thereby a form of scientific impact.

\section{Limitations and Agenda}

Our study is subject to a number of limitations that provide opportunities for future research. First and foremost, the small size and disciplinary focus of the sample allow for only limited inferences beyond the faculty and its discipline. By extending the study to other research domains, future analyses can account for disciplinary idiosyncrasies. Furthermore, studies considering the entire social graph of the SNS platform could tackle a range of open questions and challenges. Such comprehensive (network) data might, however, not be immediately available and subject to privacy restrictions. To date, ResearchGate does not provide direct access to the necessary data.

A second limitation concerns the platform itself and our reliance on it as the unique source of relational data. The platform provides specific functionalities and promotes specific online activities, thereby potentially biasing the results of our analysis. Researchers use a range of different social media tools (Gruzd \& Goertzen, 2013), and future research should consider interaction streams on different platforms. Network data from different academic SNS are necessary to further answer the question of what constitutes and drives academic influence on SNS.

Third, the data at hand reveal only basic attribute characteristics. More detailed descriptions of the involved researchers are necessary to address questions of influence on social media, and especially academic SNS, including, but not limited to, career tracks, web skills, affinity and attitudes, trust, privacy and security concerns, work environment, importance of research partnerships and sharing, etc. Survey data would therefore add valuable context to our findings. Also, qualitative approaches could be applied to generate a more fine-grained picture of how individuals perceive impact within social networks, and how they make sense of the influence landscape.

Finally, future research should look at the use of academic SNS over time. Given the necessary longitudinal data, relational metrics may be able to contribute to a more dynamic perspective on impact assessment: Researchers at various stages in their career might employ online communication tools for different purposes, such as relationship building, promotion, and information dissemination. These activities could contribute to different forms of social capital building up to increasingly institutionalized forms of 
scientific impact. Comparisons with coauthorship networks could further enlighten the interrelation between personal networks and the resulting accumulation of academic capital.

\section{References}

Aguinis, H., Suárez-González, I., Lannelongue, G., \& Joo, H. (2012). Scholarly impact revisited. Academy of Management Perspectives, 26(2), 105-132.

Archambault, A., \& Grudin, J. (2012). A longitudinal study of facebook, linkedin, \& twitter use. Proceedings of the 2012 ACM Annual Conference on Human Factors in Computing Systems CHI 12, 2741.

Bastian, M., Heymann, S., \& Jacomy, M. (2009). Gephi: An open source software for exploring and manipulating networks. Artificial Intelligence, 2(2), 361-362.

Bik, H.M., \& Goldstein, M.C. (2013). An introduction to social media for scientists. PLoS Biology, 11(4), e1001535. Retrieved from http:// www.plosbiology.org/article/info\%3Adoi\%2F10.1371\%2Fjournal.pbio .1001535

Bollen, J., Van De Sompel, H., Hagberg, A., \& Chute, R. (2009). A principal component analysis of 39 scientific impact measures. PLoS ONE, 4(6), e6022. Retrieved from http://www.plosone.org/article/info\%3 Adoi\%2F10.1371\%2Fjournal.pone.0006022

Borgatti, S.P., Everett, M.G., \& Freeman, L.C. (2002). Ucinet for Windows: Software for social network analysis. Harvard Analytic Technologies, SNA Analysis software.

Borgatti, S.P., Mehra, A., Brass, D.J., \& Labianca, G. (2009). Network analysis in the social sciences. Science, 323(5916), 892-895.

Bornmann, L. (2013). Is there currently a scientific revolution in scientometrics? Journal of the American Society for Information Science and Technology, 65(3), 647-648.

Bornmann, L., \& Daniel, H.-D. (2008). What do citation counts measure? A review of studies on citing behavior. Journal of Documentation, 64(1), 45-80.

Bourdieu, P. (1984). Distinction: A social critique of the judgement of taste. Cambridge, MA: Harvard University Press.

Bourdieu, P. (1990). Homo academicus. Palo Alto, CA: Stanford University Press.

Bourdieu, P. (1996). The rules of art: Genesis and structure of the literary field. Palo Alto, CA: Stanford University Press.

boyd, d., \& Ellison, N.B. (2007). Social network sites: Definition, history, and scholarship. Journal of Computer-Mediated Communication, 13(1), 210-230.

Crane, D. (1972). Invisible colleges: Diffusion of knowledge in scientific communities. Chicago: University of Chicago Press.

Desai, T., Shariff, A., Shariff, A., Kats, M., Fang, X., Christiano, C., \& Ferris, M. (2012). Tweeting the meeting: An in-depth analysis of Twitter activity at Kidney Week 2011. PLoS One, 7(7), e40253. Retrieved from http://www.plosone.org/article/info\%3Adoi\%2F10.1371\%2Fjournal .pone. 0040253

Dimitrova, D., Gruzd, A., Hayat, Z., Mo, G.Y., Mok, D., Robbins, T., (. . ), \& Zhuo, X. (2013). NAVEL gazing: Studying a networked scholarly organization. In K. Evangelos (Ed.), Advances in network analysis and its applications (pp. 287-313). Berlin: Springer. Retrieved from http:// groups.chass.utoronto.ca/netlab/wp-content/uploads/2012/05/NAVEL -Gazing-Studying-a-Networked-Scholarly-Organization.pdf

Ellison, N.B., Steinfield, C., \& Lampe, C. (2007). The benefits of Facebook "friends": Social capital and college students' use of online social network sites. Journal of Computer-Mediated Communication, 12(4), 1143-1168.

Emirbayer, M. (1997). Manifesto for a relational sociology. American Journal of Sociology, 103(2), 281-317.

Ewing, T. (2008). Participation cycles and emergent cultures in an online community. International Journal of Market Research, 50(5), 575-590.

Eysenbach, G. (2011). Can Tweets predict citations? Metrics of social impact based on Twitter and correlation with traditional metrics of scientific impact. Journal of Medical Internet Research, 13(4), 1-15. Retrieved from http://www.jmir.org/2011/4/e123/

Freeman, L.C. (2004). The development of social network analysis-A study in the sociology of science. North Charleston, SC: Booksurge Llc.

Garfield, E. (2003). The meaning of the impact factor. International Journal of Clinical and Health Psychology, 3(2), 363-369.

Giglia, E. (2011). Academic social networks: It's time to change the way we do research. European Journal of Physical and Rehabilitation Medicine, 47(2), 345-350.

Glänzel, W., \& Schubert, A. (2005). Analysing scientific networks through co-authorship. In H.F. Moed, W. Glänzel, \& U. Schmoch (Eds.), Handbook of quantitative science and technology research (pp. 257-276). Dordrecht, Netherlands: Kluwer Academic Publishers/Springer.

Gruzd, A., \& Goertzen, M. (2013). Wired Academia: Why social science scholars are using social media. Proceedings of the 46th Hawaii Conference on System Sciences, 3332-3341.

Hanneman, R.A., \& Riddle, M. (2011). Concepts and measures for basic network analysis. In J. Scott \& P.J. Carrington (Eds.), The SAGE handbook of social network analysis (pp. 340-369). Thousand Oaks, CA: Sage.

Harzing, A.W. (2007) Publish or Perish. Retrieved from http://www harzing.com/pop.htm

Hirsch, J.E. (2005). An index to quantify an individual's scientific research output. Proceedings of the National Academy of Sciences of the United States of America, 102(46), 16569-16572.

Hirsch, J.E. (2007). Does the h-index have predictive power? Proceedings of the National Academy of Sciences of the United States of America, 104(49), 19193-19198.

Hughes, D.J., Rowe, M., Batey, M., \& Lee, A. (2012). A tale of two sites: Twitter vs. Facebook and the personality predictors of social media usage. Computers in Human Behavior, 28(2), 561-569.

Jeng, W., He, D., \& Jiang, J. (2014). User participation in an academic social networking site: A survey of open group users on Mendeley. Journal of the Association for Information Science and Technology, forthcoming.

Koku, E., Nazer, N., \& Wellman, B. (2000). Netting scholars: Online and offline. American Behavioral Scientist, 44(10), 1-19.

Kousha, K., Thelwall, M., \& Rezaie, S. (2010). Using the web for research evaluation: The integrated online impact indicator. Journal of Informetrics, 4(1), 124-135.

Leydesdorff, L. (2007). Betweenness centrality as an indicator of the interdisciplinarity of scientific journals? Journal of the American Society for Information Science and Technology, 58(9), 1303-1319.

Mahrt, M., Weller, K., \& Peters, I. (2013). Twitter in scholarly communication. In K. Weller, A. Bruns, J. Burgess, M. Mahrt, \& C. Puschmann (Eds.), Twitter and society (pp. 399-410). New York, Bern, Berlin, Bruxelles, Frankfurt a. M., Oxford, Vienna: Peter Lang.

Moody, J. (2004). The structure of a social science collaboration network: Disciplinary cohesion from 1963 to 1999. American Sociological Review, 69(2), 213-238.

Mounce, R. (2013). Open access and altmetrics: Distinct but complementary. Bulletin of the American Society for Information Science and Technology, 39(4), 14-17.

Nentwich, M., \& König, R. (2012). Cyberscience 2.0-Research in the age of digital social networks. Frankfurt and New York: Campus.

Nielsen, M. (2012). Reinventing discovery: The new era of networked science. Princeton, NJ: Princeton University Press.

Nov, O., Naaman, M., \& Ye, C. (2009). Analysis of participation in an online photo-sharing community: A multidimensional perspective. Journal of the American Society for Information Science and Technology, 61(3), 555-566.

Pénard, T., \& Poussing, N. (2010). Internet use and social capital: The strength of virtual ties. Journal of Economic Issues, 44(3), 569595.

PLoS Medicine Editors. (2006). The impact factor game. PLoS Medicine, 3(6), e291. Retrieved from http://www.plosmedicine.org/article/info:doi/ 10.1371/journal.pmed.0030291

Priem, J. (2013). Scholarship: Beyond the paper. Nature, 495, 437-440. 
Priem, J., \& Costello, K.L. (2010). How and why scholars cite on Twitter. Proceedings of the 73rd ASIST Annual Meeting, 1-4.

Priem, J., \& Hemminger, B.H. (2010). Scientometrics 2.0: New metrics of scholarly impact on the social Web. First Monday, 15(7-5).

Priem, J., Taraborelli, D., Groth, P., \& Neylon, C. (2010). Alt-metrics: A manifesto. October. Retrieved from http://altmetrics.org/manifesto/

Procter, R., Williams, R., Stewart, J., Poschen, M., Snee, H., Voss, A., . . . (2010). Adoption and use of Web 2.0 in scholarly communications. Philosophical Transactions. Series A, Mathematical, Physical, and Engineering Sciences, 368(1926), 4039-4056.

Quan-Haase, A., \& Young, A.L. (2010). Uses and gratifications of social media: A comparison of Facebook and instant messaging. Bulletin of Science, Technology \& Society, 30(5), 350-361.

Scott, J., \& Carrington, P.J. (2011). The Sage handbook of social network analysis. Thousand Oaks, CA: Sage.

Seglen, P.O. (1997). Why the impact factor of journals should not be used for evaluating research. BMJ British Medical Journal, 314(7079), 498502.

Shema, H., Bar-Ilan, J., \& Thelwall, M. (2012). Research blogs and the discussion of scholarly information. PLoS One, 7(5), e35869. Retrieved from http://www.plosone.org/article/info\%3Adoi\%2F10.1371\%2 Fjournal.pone.0035869

Thelwall, M. (2012). Journal impact evaluation: A webometric perspective. Scientometrics, 92(2), 429-441.

Thelwall, M., \& Harries, G. (2004). Do the web sites of higher rated scholars have significantly more online impact? Journal of the American Society for Information Science and Technology, 55(2), 149-159.

Thelwall, M., \& Kousha, K. (2014a). ResearchGate: Disseminating, communicating and measuring scholarship. Journal of the Association for Information Science and Technology, forthcoming.

Thelwall, M., \& Kousha, K. (2014b). Academia.edu: Social network or academic network? Journal of the Association for Information Science and Technology, 65(4), 721-731.

Thelwall, M., Sud, P., \& Wilkinson, D. (2012). Link and co-inlink network diagrams with URL citations or title mentions. Journal of the American Society for Information Science and Technology, 63(4), 805-816.

Valenzuela, S., Park, N., \& Kee, K.F. (2009). Is there social capital in a social network site? Facebook use and college students' life satisfaction, trust, and participation. Journal of Computer-Mediated Communication, 14(4), 875-901.

Vaughan, L., \& Hysen, K. (2002). Relationship between links to journal Web sites and impact factors. Aslib Proceedings, 54(6), 356-361.

Vaughan, L., \& Shaw, D. (2003). Bibliographic and web citations: What is the difference? Journal of the American Society for Information Science and Technology, 54(14), 1313-1322.
Wasserman, S., \& Faust, K. (1994). Social network analysis: Methods and applications. Cambridge, MA: Cambridge University Press.

Watts, D.J., \& Strogatz, S.H. (1998). Collective dynamics of "small-world" networks. Nature, 393(6684), 440-442.

Wellman, B., Quan-Haase, A., Witte, J., \& Hampton, K. (2001). Does the internet increase, decrease, or supplement social capital?: Social networks, participation, and community commitment. American Behavioral Scientist, 45(3), 436-455.

White, H.D. (2011). Scientific and scholarly networks. In J. Scott \& P.J. Carrington (Eds.), The SAGE handbook of social network analysis (pp. 271-285). Thousand Oaks, CA: Sage.

White, H.D., Wellman, B., \& Nazer, N. (2004). Does citation reflect social structure? Longitudinal evidence from the "globenet" interdisciplinary research group. Journal of the American Society for Information Science, 55(2), 111-126.

Yan, E., \& Ding, Y. (2009). Applying centrality measures to impact analysis: A coauthorship network analysis. Journal of the American Society for Information Science, 60(10), 2107-2118.

Yan, E., \& Ding, Y. (2012). Scholarly network similarities: How bibliographic coupling networks, citation networks, cocitation networks, topical networks, coauthorship networks, and coword networks relate to each other. Journal of the American Society for Information Science, 63(7), 1313-1326

\section{Appendices}

\section{Appendix A1: Distribution of Engagement Index (Normalized)}

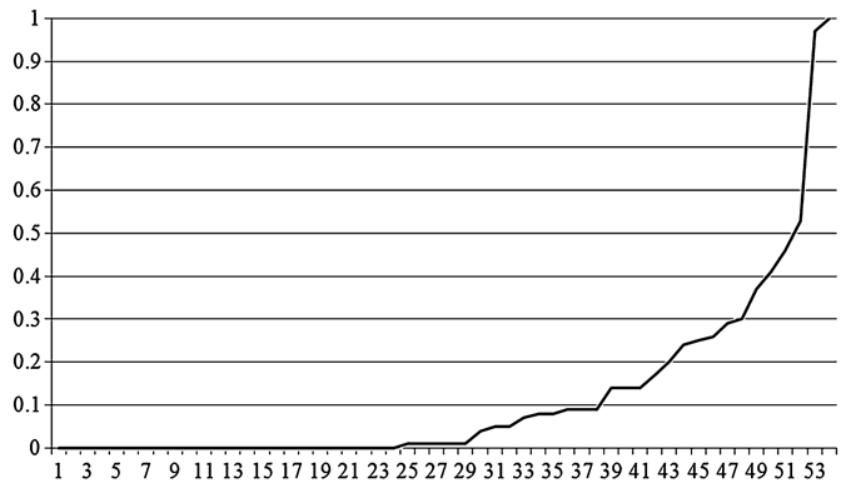

Appendix A2: Correlation Table

\begin{tabular}{|c|c|c|c|c|c|c|c|c|c|c|c|c|c|c|c|c|}
\hline & & 2 & 3 & 4 & 5 & 6 & 7 & 8 & 9 & 10 & 11 & 12 & 13 & 14 & 15 & 16 \\
\hline 1 & $\begin{array}{l}\text { Platform Engagement } \\
\text { Centrality }\end{array}$ & $0.64 * *$ & $0.54 * *$ & $0.35^{* *}$ & $0.59 * *$ & $0.55^{* *}$ & n.s. & n.s. & n.s. & n.s. & n.s. & n.s. & n.s. & n.s. & n.s. & n.s. \\
\hline 2 & OI & & $0.79 * *$ & $0.56^{* *}$ & $0.44 * *$ & $0.74 * *$ & $0.48^{* *}$ & $0.46^{* *}$ & $0.53 * *$ & $0.51 * *$ & $0.50 * *$ & $0.48 * *$ & $0.43^{* *}$ & $0.41 * *$ & n.s. & n.s. \\
\hline 3 & SI & & & $0.71^{* *}$ & $0.61 * *$ & $0.94 * *$ & $0.30 *$ & n.s. & $0.36^{* *}$ & n.s. & $0.37 * * *$ & $0.31 * * *$ & $0.30^{*}$ & n.s. & $0.41 * *$ & $0.38 * *$ \\
\hline 4 & C & & & & n.s. & $0.71^{* *}$ & $0.39 * *$ & $0.34 *$ & $0.44 * *$ & $0.32 *$ & $0.42 * *$ & $0.39 * *$ & $0.35^{* *}$ & n.s. & n.s. & n.s. \\
\hline 5 & B & & & & & $0.49 * *$ & n.s. & n.s. & n.s. & n.s. & n.s. & n.s. & n.s. & n.s. & n.s. & n.s. \\
\hline 6 & $\mathrm{EV}$ & & & & & & $0.33^{*}$ & $0.28 *$ & $0.42 * *$ & $0.27 *$ & $0.32 *$ & $0.34 *$ & $0.35^{*}$ & n.s. & n.s. & n.s. \\
\hline 7 & Publication Resonance & & & & & & & $0.87 * *$ & $0.79 * *$ & $0.85 * *$ & $0.32 * *$ & $0.79 * *$ & $0.89^{* *}$ & $0.79 * *$ & n.s. & $0.73 * *$ \\
\hline 8 & Publication Success & & & & & & & & $0.84 * *$ & $0.87 * *$ & $0.35^{*}$ & $0.82 * *$ & $0.89^{* *}$ & $0.92 * *$ & n.s. & $0.93 * *$ \\
\hline 9 & Seniority & & & & & & & & & $0.81 * *$ & $0.39 * *$ & $0.84 * *$ & $0.85^{* *}$ & $0.64 * *$ & n.s. & $0.67 * *$ \\
\hline 10 & ResearchGate Score & & & & & & & & & & $0.44^{* * *}$ & $0.77 * *$ & $0.78^{* *}$ & $0.79 * *$ & n.s. & $0.79 * *$ \\
\hline 11 & Duration of Membership & & & & & & & & & & & $0.50 * *$ & $0.34 *$ & n.s. & n.s. & n.s. \\
\hline 12 & Number of Co-Authors & & & & & & & & & & & & $0.83^{* *}$ & $0.62 * *$ & n.s. & $0.65 * *$ \\
\hline 13 & Number of Publications & & & & & & & & & & & & & $0.75 * *$ & $0.29 *$ & $0.68 * *$ \\
\hline 14 & Total No. of Citations & & & & & & & & & & & & & & n.s. & $0.95 * *$ \\
\hline 15 & Publication Coverage & & & & & & & & & & & & & & & n.s. \\
\hline
\end{tabular}

Note. 16 = average number of citations per publication; $\mathrm{N}=55 ; \mathrm{n} . \mathrm{s} .=$ not significant; Pearson correlation coefficients

$* p<.05$

$* * p<.01$. 